\title{
NeuroRegulation
}

\section{EEG Patterns Under Positive/Negative Body Postures and Emotion Recall Tasks}

\author{
Hsin-Yi Tsai ${ }^{1}$, Erik Peper ${ }^{2}$, and I-Mei Lin ${ }^{1 *}$ \\ ${ }^{1}$ Department of Psychology, College of Humanities and Social Sciences, Kaohsiung Medical University, Taiwan \\ ${ }^{2}$ Institute for Holistic Health Studies, San Francisco State University, California, USA
}

\begin{abstract}
Introduction: Erect and slouch body postures affect access to positive and negative emotions. In an erect sitting posture participants reported more positive emotion and thoughts, while in a slouch position they reported more negative emotion and thoughts. This study explored the electroencephalogram (EEG) patterns under erect and slouch body postures while recalling positive and negative events. Methods: Twenty-eight healthy college students were instructed to sit quietly with their eyes closed for $1 \mathrm{~min}$, and then to sit in erect or slouch postures while recalling happy or depressive events for 1 min each. EEG, with linked-ear references, was recorded at $\mathrm{Cz}$ and analyzed under five conditions. Results: There were significantly higher amplitudes of beta2, beta3, and beta4 in a slouch posture while recalling happy events than in an erect posture while recalling happy or depressive events. There was no significant difference between body posture and emotional recall on lowfrequency oscillatory activity. The reaction time was significantly longer to access positive event in the slouched position as compared to the erect position. Conclusion: Evoking positive thoughts in a slouch body position takes more effort or arousal than other positions as indicated by the significant increase in high-frequency oscillatory activities. The implication for cognitive behavior therapy is that body posture matters; clients have more difficulty shifting to evoking a positive emotional state when sitting in a collapsed position than when sitting in an erect position.
\end{abstract}

Keywords: electroencephalogram; body posture; emotional recall; depression

Citation: Tsai, H.-Y., Peper, E., \& Lin, I.-M. (2016). EEG Patterns Under Positive/Negative Body Postures and Emotion Recall Tasks. NeuroRegulation, 3(1), 23-27. http://dx.doi.org/10.15540/nr.3.1.23

*Address correspondence to: I-Mei Lin, PhD, 100, Shih-Chuan 1st

Road, Kaohsiung 80708, Taiwan. Email: psyiml@kmu.edu.tw

Edited by:

Nancy L. Wigton, PhD, Grand Canyon University, Phoenix, Arizona, USA

Copyright: (C) 2016. Tsai et al. This is an Open Access article distributed under the terms of the Creative Commons Attribution License (CC-BY).

Reviewed by:

Rex Cannon, PhD, Neural Potential, Boynton Beach, Florida, USA Randall Lyle, PhD, Mount Mercy University, Cedar Rapids, Iowa, USA

\section{Introduction}

Body posture might affect our mental state, emotion, and memory recall (Michalak, Micschnat, \& Teismann, 2014; Peper \& Lin, 2012). Peper and Lin have found that walking in a slouch posture may decrease subjective energy and increase negative emotion, such as sadness, loneliness, isolation, and sleepiness. This slouch posture accompanied feelings of "wanting to just sit down", "low energy," "depressive feelings," or being "zombie-like." While walking in an erect posture and skipping, participants increased their subjective energy and experienced more energetic, happy, and positive feeling. In addition, they found that the erect posture makes subjects much stronger to resist the downward pressure compared to the collapsed position. Nair et al. (2015) found that a slumped posture compared to an upright posture increased the emotional state of high negative arousals including fear, hostility, and nervousness. They also found that an upright-seated posture compared to a slumped posture had a protective effect on the emotion when experiencing a psychological stressor.

The effect of posture on access to positive or negative memories was demonstrated by Wilson and Peper (2004), who found that negative thoughts and memories were easier to access in a collapsedslump position and that positive thoughts were easier to access when sitting in an upright position. 
Michalak et al. (2014) found that patients with depression recalled more negative words in a slump posture, which indicated a recall bias depending upon posture. However, the recall bias of positive and negative words did not occur under an upright sitting posture.

Thibault, Lifshitz, Jones, and Raz (2014) and Zhavoronkova, Zharikova, Kushnir, and Mikhalkova (2012) explored the associations between changes in body posture and electroencephalogram (EEG) activity. Thibault et al. found increased beta (14-30 $\mathrm{Hz}$ ) and gamma $(30-50 \mathrm{~Hz})$ activities in the frontal and occipital regions from lying supine to $45^{\circ}$ recline, as well as from $45^{\circ}$ recline to sitting upright. Zhavoronkova et al. also found that there were increased beta (12.3-30.1 Hz) and gamma (30.1$40.2 \mathrm{~Hz}$ ) activities at the parietal and occipital areas from lying to sitting position, whereas there were decreased delta $(2.0-3.9 \mathrm{~Hz})$, theta $(4.3-7.8 \mathrm{~Hz})$, and alpha (8.1-12.1 Hz) activities from lying to sitting position. In addition, there were increased alpha2 $(10.5-12.1 \mathrm{~Hz})$, beta $(12.3-30.1 \mathrm{~Hz})$, and gamma (30.1-40.2 Hz) activities from sitting to upright positions (Zhavoronkova et al., 2012). Changes in body posture (e.g., from lying supine to sitting, from sitting to upright) increase highfrequency oscillatory activities.

Previous studies have confirmed changes in body posture related to subject's feelings, memory recall, and brain activity. However, the brain activity when combining the body posture and emotional recall is unknown. The purpose of this study was to explore the EEG patterns under erect or slouch postures while recalling happy or depressive events.

\section{Methods}

\section{Participants}

Twenty-nine college students were recruited from the Kaohsiung Medical University; one participant was excluded from data analysis due to EEG recording problems. The mean age of the students was 20.64 years $(S D=1.06)$ with 3 men and 25 women. All participants were instructed not to drink caffeinated beverages on the day of the study. Institutional Review Board approval was obtained from the ethics committee of the Kaohsiung Medical University Hospital, and written informed consent was obtained from each participant before the experiment.

\section{Experimental Procedure}

Participants were asked to fill out demographic and psychological questionnaires and then sat in a comfortable posture on a sofa. The research procedure consisted of a 2 (erect and slouch postures; Figure 1) $\times 2$ (recalling happy or depressive events) Latin Square design.

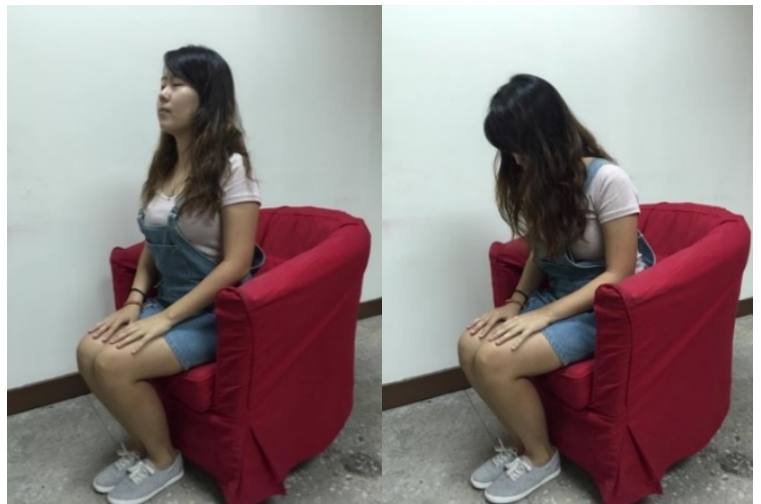

Figure 1. The erect and slouch postures.

The experimental stages consisted of a 1-min resting baseline with eyes closed, and then the participants were assigned randomly to experience A-D stages with eyes closed for 1 min each (Figure 2): (A) erect posture while recalling happy event; (B) erect posture while recalling depressive event; (C) slouch posture while recalling happy event; or (D) slouch posture while recalling depressive event.

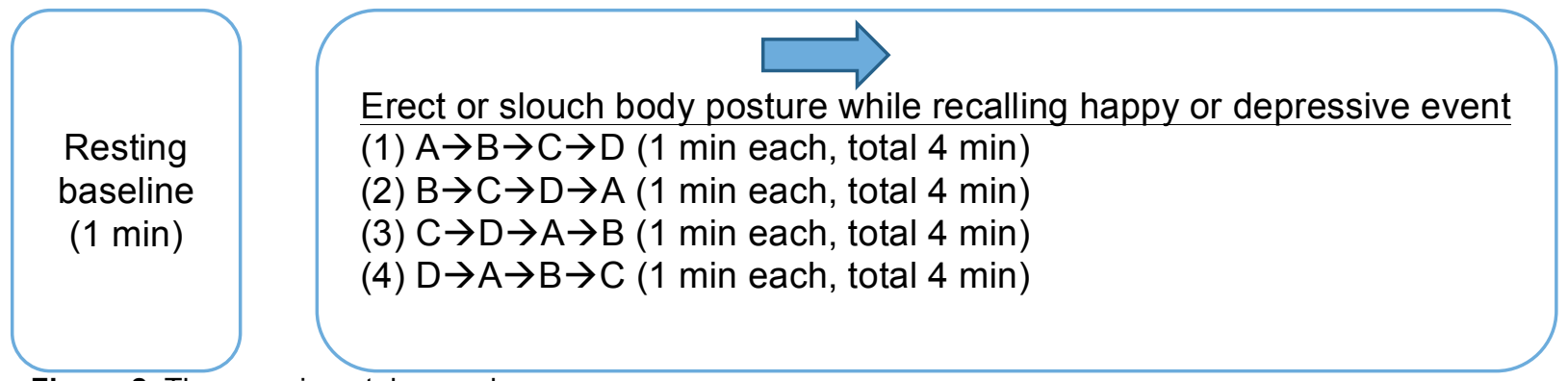

Figure 2. The experimental procedure. 
In the erect posture participants were asked to look up and straighten their back, whereas in the slouch posture participants were asked to lower their heads, look down, and sit hunch-backed. The instructions for recalling happy and depressive events were as follows:

Instructions for recalling a happy event: Please keep the same posture and recall a happy memory from your past. We experience joyful things such as doing the activities we enjoy, getting good scores on exams, gathering with friends, and striving for success. The feeling is very happy and joyful. Now please recall something happy. When you recall such a memory, let me know with a nod. Please maintain the happy feeling for $1 \mathrm{~min}$. When the time is up, I will let you know.

Instructions for recalling a depressive event: Please keep the same posture and recall a depressive memory from your past. We experience melancholy such as feeling hopeless and helpless, pressure from work, or the stress of school, work, and relationships. The feeling is very depressing and sad. Now please recall something depressive. When you recall such a memory, let me know with a nod. Please maintain the depressive feeling for $1 \mathrm{~min}$. When the time is up, I will let you know.

After recalling a happy or a depressive event, participants were asked to rate a score from 0 to 100 in relation to how easy it was to recall that event $(0=$ not easy at all, 100 = extremely easy). The reaction time was recorded when participants nodded their head to tell the researcher that they had a happy or a depressive event come into their mind.

\section{EEG Recording}

The one-channel EEG sensor was recorded from $\mathrm{Cz}$ with linked-ear reference based on the International 10-20 system. EEG signals were recorded using BioGraph Infiniti software (Version 6.0.4, n.d.) with a band-pass between 1-30 Hz. The sample rate was $256 \mathrm{~Hz}$ with $60-\mathrm{Hz}$ notch filters, and the electrode impedances were lower than $5 \mathrm{k} \Omega$.

\section{Data Reduction and Statistical Analysis}

After removing eye-blink and movement artifacts, the raw signals of the EEG were analyzed to calculate the EEG amplitude using the following bandwidth: total theta $(4-8 \mathrm{~Hz})$, total alpha (8-12 $\mathrm{Hz})$, total beta $(12-32 \mathrm{~Hz})$, beta1 $(12-15 \mathrm{~Hz})$, beta2 (15-22 Hz), beta3 $(22-28 \mathrm{~Hz})$, and beta4 (28-32 $\mathrm{Hz}$ ) from the five experimental stages. One-way analysis of variance (ANOVA) with repeated measures was used to examine the differences in the EEG amplitudes under the five experimental stages. The analysis was performed using SPSS predictive analytics software (Version 20.0).

\section{Results}

The participants reported that it was significantly easier to evoke depressive events in the slouch posture than in the erect posture (70.45 and 63.45), and evoke happiness events in the erect posture than in the slouch posture (80.69 and 73.83), as shown in Table 1. It took significantly longer to recall happy events $(7.33 \mathrm{~s})$ in the collapsed position than erect position (3.85 s). In addition, there was shorter reaction time in erect posture for recalling happy events than other conditions $(F=3.52, p$ $<.5)$.

\section{Table 1}

The score of ease to recall and reaction time under different experimental stages.

\begin{tabular}{|c|c|c|c|c|c|c|}
\hline Variables & $\begin{array}{l}\text { Erect while } \\
\text { recalling } \\
\text { happy event } \\
\text { (A) }\end{array}$ & $\begin{array}{l}\text { Erect while } \\
\text { recalling } \\
\text { depressive } \\
\text { event } \\
\quad \text { (B) }\end{array}$ & $\begin{array}{l}\text { Slouch while } \\
\text { recalling } \\
\text { happy event } \\
\text { (C) }\end{array}$ & $\begin{array}{l}\text { Slouch while } \\
\text { recalling } \\
\text { depressive } \\
\text { event } \\
\text { (D) }\end{array}$ & $F$ & $\begin{array}{l}\text { Post hoc } \\
\text { Comparison }\end{array}$ \\
\hline Score of ease to recall & $80.69(13.21)$ & $63.45(23.83)$ & $73.83(20.34)$ & $70.45(19.98)$ & $4.26^{*}$ & $\begin{array}{l}1>2,4 ; \\
4>2\end{array}$ \\
\hline
\end{tabular}

Note. ${ }^{*} p<.05$. 
There were significant differences between the five stages in total beta, beta2, beta3, and beta4 $(F=$ $4.01, p<.05 ; F=4.93, p<.01 ; F=9.77, p<.001$; and $F=17.87, p<.001$, respectively). The post hoc comparison found the following results (Table 2): (1) while recalling a happy event, there were significantly higher amplitudes of total beta, beta2, beta3, and beta4 in a slouch posture than in an erect posture; (2) while recalling a depressive event, there were significantly higher amplitudes of beta3 and beta4 in a slouch posture than in an erect posture; (3) under congruent body posture and emotional event (sitting collapsed and recalling depressive events; sitting erect and recalling positive events), there was no significant difference in brain activity between the experimental stages; and (4) under incongruent body posture and emotional event (sitting collapsed and recalling positive emotional events; sitting erect and recalling depressive events), there were significantly higher amplitudes of beta2, beta3, and beta4 in a slouch posture with recalling happy events than in an erect posture with recalling depressive events.

\section{Table 2}

The EEG amplitude under different experimental stages.

\begin{tabular}{|c|c|c|c|c|c|c|c|}
\hline Variables & Baseline & $\begin{array}{l}\text { Erect while } \\
\text { recalling } \\
\text { happy event } \\
\text { (A) }\end{array}$ & $\begin{array}{l}\text { Erect while } \\
\text { recalling } \\
\text { depressive } \\
\text { event } \\
\text { (B) }\end{array}$ & $\begin{array}{l}\text { Slouch while } \\
\text { recalling } \\
\text { happy event } \\
\text { (C) }\end{array}$ & $\begin{array}{l}\text { Slouch while } \\
\text { recalling } \\
\text { depressive } \\
\text { event } \\
\text { (D) }\end{array}$ & $F$ & $\begin{array}{l}\text { Post hoc } \\
\text { Comparison }\end{array}$ \\
\hline Total theta & $12.51(5.60)$ & $11.27(5.22)$ & $11.62(5.58)$ & $11.49(5.46)$ & $11.58(5.38)$ & $6.00^{* * *}$ & $1>2,3,4,5$ \\
\hline Total alpha & $16.86(6.10)$ & $15.00(6.35)$ & $15.26(6.53)$ & $15.44(6.13)$ & $15.33(6.53)$ & $4.09^{* *}$ & $1>2$ \\
\hline Total beta & $10.37(2.26)$ & $9.94(2.56)$ & $9.87(2.50)$ & $10.73(2.66)$ & $10.70(2.97)$ & $4.01^{*}$ & $\begin{array}{l}1>3 \\
4>2\end{array}$ \\
\hline Beta1 & $5.20(1.45)$ & $5.02(1.55)$ & $5.14(1.55)$ & $5.24(1.73)$ & $5.31(1.71)$ & 1.02 & \\
\hline Beta2 & $6.60(1.49)$ & $6.10(1.57)$ & $6.09(1.60)$ & $6.64(1.64)$ & $6.60(1.85)$ & $4.93^{* *}$ & $\begin{array}{l}1>2,3 \\
4>2,3\end{array}$ \\
\hline Beta3 & $4.16(0.88)$ & $4.14(0.98)$ & $4.00(1.04)$ & $4.72(1.10)$ & $4.65(1.35)$ & $9.77^{* * *}$ & $\begin{array}{l}4>1,2,3 \\
5>3\end{array}$ \\
\hline Beta4 & $2.80(0.54)$ & $2.74(0.59)$ & $2.61(0.66)$ & $3.45(0.77)$ & $3.24(0.95)$ & $17.87^{\star * \star}$ & $\begin{array}{l}1>3 \\
4>1,2,3 \\
5>1,3\end{array}$ \\
\hline
\end{tabular}

Note. ${ }^{*} p<.05 .{ }^{* *} p<.01 .{ }^{* * *} p<.001$.

(1) $4>3$ indicated that under incongruent of body posture and emotion recall there were higher beta2, beta3, and beta4 at slouch posture while recalling happiness event than that at erect posture while recalling depressive event.

(2) $4>2$ indicated that under recalling happy events there were higher beta 2 , beta3, and beta 4 at slouch posture than at erect posture.

\section{Discussion}

The initial results of this study found that the collapsed posture while recalling positive emotional events had higher beta activities than the other conditions. These results were consistent with the findings of Thibault et al. (2014) and Zhavoronkova et al. (2012) who found increased high-frequency brain activity (such as beta and gamma) under changing body posture. However, this study found that, independent of the body position, recalling happy events in a collapsed position significantly increased the high-frequency oscillatory activity than recalling depressive event in an erect posture. This suggests that it takes much more effort and time to evoke and maintain positive thoughts in a collapsed position. This was also confirmed by the significant increase in reaction time when attempting to recall positive events in the collapsed body position as compared to the erect body position.

This may have significant implications for people who are depressed. Most depressed people or patients have a slumped collapsed posture which would inhibit accessing positive thoughts, thus augmenting their depressive thoughts. To increase 
the access to positive thoughts, the person would need to sit erect and look up. In this position, positive and negative thoughts can equally be accessed. Most likely these patterns have been classically conditioned since early childhood.

The EEG findings could explain why subjects reported that it was easier to evoke depressive events as compared to happy events in a collapsed posture because it took more effort and time to think of positive thoughts as indicated by the increase in beta amplitude and reaction time. The EEG finding could not explain why positive thoughts were more easily recalled in the upright posture. Possibly other EEG locations (e.g., left and right frontal) should have been recorded, or an explanation may be because the subjects were healthy students without a history of depression.

Several limitations should be noted in this study. First, most participants were women and gender differences may influence EEG patterns. Second, the recall of memory was a subjective experience, and the quality and intensity of the memory recall may vary between participants, which could affect the findings. Third, the exact psychophysiological mechanisms of posture and emotional regulation remain unknown. Fourth, the EEG recording was only from $\mathrm{Cz}$, and possibly other locations such as frontal EEG may offer more information. Fifth, the study was a cross-sectional study of college students, which limits the generalization to other populations.

In conclusion, this study indicated that body postures and emotional recall were related to highfrequency brainwaves inhibiting the access of positive thoughts in a collapsed position. The finding may have significant implications for people who experience depression. Sitting collapsed will tend to increase access to negative thoughts and emotions and limit access to positive thoughts and emotions, while sitting erect will tend to increase access of positive thoughts and emotions.

\section{Acknowledgements}

We greatly thank San-Yu Wang, Ying-Ju Chen, Chia-I Ko, and Pin-Chun Chou for data collection.

\section{References}

Michalak, J., Mischnat, J., \& Teismann, T. (2014). Sitting posture makes a difference-embodiment effects on depressive memory bias. Clinical Psychology and Psychotherapy, 21(6), 519-524. http://dx.doi.org/10.1002/cpp.1890

Nair, S., Sagar, M., Sollers III, J., Consedine, N., \& Broadbent, E. (2015). Do slumped and upright postures affect stress responses? A randomized trial. Health Psychology, 34(6), 632-641. http://dx.doi.org/10.1037/hea0000146

Peper, E., \& Lin, I.-M. (2012). Increase or decrease depression: How body postures influence your energy level. Biofeedback, 40(3), 125-130. http://dx.doi.org/10.5298 /1081-5937-40.3.01

Thibault, R. T., Lifshitz, M., Jones, J. M., \& Raz, A. (2014). Posture alters human resting-state. Cortex, 58, 199-205. http://dx.doi.org/10.1016/j.cortex.2014.06.014

BioGraph Infiniti (Version 6.0.4) [Computer software]. Quebec, Canada: Thought Technology Ltd. Retrieved from: http://thoughttechnology.com/index.php/software/biographinfiniti-software-platform.html

Wilson, V. E., \& Peper, E. (2004). The effects of upright and slumped postures on the recall of positive and negative thoughts. Applied Psychophysiology and Biofeedback, 29(3), 189-195. /B:APBI.0000039057.32963.34

Zhavoronkova, L. A., Zharikova, A. V., Kushnir, E. M., \& Mikhalkova, A. A. (2012). EEG markers of upright posture in healthy individuals. Human Physiology, 38(6), 604-612. http://dx.doi.org/10.1134/S0362119712050131

Received: February 19, 2016

Accepted: March 5, 2016

Published: March 9, 2016 